Association for Information Systems AIS Electronic Library (AISeL)

2008

\title{
Customer Portfolio Analysis Using the SOM
}

Annika H. Holmbom

Turku Centre for Computer Science (TUCS) Åbo Akademi University Turku, Finland, annika.h.holmbom@abo.fi

Tomas Eklund

Institute for Integrated and Intelligent Systems (IIIS) Griffith University Brisbane, Australia, tomas.eklund@abo.fi

Barbro Back

Department of Information Technologies Åbo Akademi University Turku, Finland, barbro.back@abo.fi

Follow this and additional works at: http://aisel.aisnet.org/acis2008

\section{Recommended Citation}

Holmbom, Annika H.; Eklund, Tomas; and Back, Barbro, "Customer Portfolio Analysis Using the SOM" (2008). ACIS 2008 Proceedings. 5.

http://aisel.aisnet.org/acis2008/5

This material is brought to you by the Australasian (ACIS) at AIS Electronic Library (AISeL). It has been accepted for inclusion in ACIS 2008 Proceedings by an authorized administrator of AIS Electronic Library (AISeL). For more information, please contact elibrary@aisnet.org. 


\title{
Customer Portfolio Analysis Using the SOM
}

\author{
Annika H. Holmbom \\ Turku Centre for Computer Science (TUCS) \\ Åbo Akademi University \\ Turku, Finland \\ Email: annika.h.holmbom@abo.fi \\ Tomas Eklund \\ Visiting researcher, Institute for Integrated and Intelligent Systems (IIIS) \\ Griffith University \\ Brisbane, Australia \\ Email: tomas.eklund@abo.fi \\ Barbro Back \\ Department of Information Technologies \\ Åbo Akademi University \\ Turku, Finland \\ Email: barbro.back@abo.fi
}

\begin{abstract}
In order to compete for profitable customers, companies are looking to add value using Customer Relationship Management (CRM). One subset of CRM is customer segmentation, which is the process of dividing customers into groups based upon common features or needs. Segmentation methods can be used for customer portfolio analysis (CPA), the process of analyzing the profitability of customers. This study was made for a case organization, who wanted to identify their profitable and unprofitable customers, in order to gain knowledge on how to develop their marketing strategies. Data about the customers were gathered from the case organization's own database. The Self-Organizing Map (SOM) was used to divide the customers into segments, which were then analyzed in light of product sales information.
\end{abstract}

\section{Keywords}

Customer Relationship Management (CRM), Customer Portfolio Analysis (CPA), Data-driven market segmentation, Self-Organizing Map (SOM)

\section{INTRODUCTION}

Customer relationship management (CRM) is an important topic of management today. The objective of CRM is to integrate sales, marketing and customer care service in order to add value for both the company and its customers (Chalmeta 2006; Datta 1996; Heinrich 2005). CRM first emerged in 1993 and has developed rapidly in recent years thanks to advances in information technology ( Buttle 2004; Rygielski et al. 2002), to become the important function that it is in today's companies. One of the most important tasks within CRM is customer segmentation, the process of identifying and grouping customers with similar profiles or requirements (Lingras et al. 2005).

The key element in CRM and customer segmentation is overall information about customers. Today, data about customers are readily available through ERPs, corporate data warehouses, and the Internet. Data can also be purchased from other companies, which has lately formed into a new category of business (Buttle 2004; Rygielski et al. 2002).

The problem is that the amount of information available for segmentation is huge and can be very challenging to deal with because of issues such as missing data, non-uniform distributions, errors, etc. The extraction of information from large databases is, therefore, often performed using data mining methods ( Berry and Linoff 2004; Berson et al. 2000; Famili et al. 1997; Rygielski et al. 2002; Shaw et al. 2001).

The purpose of the paper is to illustrate how the Self-Organizing Map (SOM) can be used for one category of CRM, customer portfolio analysis (CPA). The work builds upon the research initiated in Holmbom (2007) in which a model for segmentation of customer data was built. The model was based upon customer data provided by a case company, and the Self-Organizing Map is used to construct the model. The model was face validated 
by experts from the sales department of the case organization. The model could potentially be used to adjust marketing efforts to increase the profitability of customers.

\section{METHODOLOGY}

\section{Customer Segmentation}

Customer segmentation is an example of analytical CRM, i.e., the use of analytical tools to study customer data (Paas and Kuijlen 2001). Customer segmentation is the process of grouping customers into subgroups with similar behavior or needs, in order to better serve or target the customers (Buttle 2004; Lingras et al. 2005). The identified segments can then be more effectively targeted with suitable marketing strategies (Frank et al. 1972, p. 26; Wedel and Kamakura 1999, p. 5). Customer segmentation is also used to identify unprofitable and profitable customers in the customer base, as well as customer relationships with development potential. This is referred to as Customer Portfolio Analysis, or CPA (Buttle 2004). CPA is important as several studies have found that the 20/80 rule holds for customer profitability as well; $20 \%$ of customers account for $80 \%$ of profits, and vice versa (Kim et al. 2006; Park and Baik 2006). Although CPA is related to segmentation and can be seen as a subset of it, the purpose is different and many of the methods used are unique (Terho and Halinen 2007). CPA can beneficially be applied to analyze segments identified using segmentation methods. There are a large variety of different methods available for CPA. However, although there is a great wealth of theoretical literature surrounding CPA available, very little literature appears to show how CPA is actually being used by companies today (Terho and Halinen 2007). Much of the literature concerns mathematical optimization models, such as portfolio theory (e.g., Turnbull 1990) and customer lifetime value (e.g., Kim et al. 2006). These methods generally view the customer base in the same way as a portfolio of investments, to be managed using the same methods. There are two main bases for segmentation, i.e., demographic data, such as socioeconomic and lifestyle measures, and product specific measures, such as product usage, customer brand attitudes, brand preferences, benefits sought and response sensitivity to different marketing campaigns. Demographic data are the most commonly used base for segmentation (Frank et al. 1972; Tsai and Chiu 2004; Wedel and Kamakura 1999). Segmentation can also be divided into two major groups based upon the approach used: market-driven and data-driven segmentation. Market-driven segmentation uses data to divide customers into segments. These segments are beforehand set according to characteristics that describe a specified customer profile, e.g., one that has been determined to be profitable. Data-driven segmentation is performed on actual customer data, e.g., the shopping behavior of a customer (Berson et al. 2000).

As for CPA, there are a large variety of methods available for segmentation. Many commonly used segmentation methods belong to the family of clustering approaches. Most of the methods in this area are statistical tools, such as k-means clustering and hierarchical clustering methods. Data mining approaches, such as sequence analysis, market basket analysis and neural networks are also employed. Other commonly used approaches are decision tree-related approaches (e.g., CHAID) and fuzzy clustering approaches (e.g., Fuzzy FCM). In this study, a data-driven exploratory CPA, based upon demographic data and coupled with product sales information, will be performed.

\section{The Data}

The data were provided by a case company that sells products ranging from simple periodicals to advanced consulting services, to other companies (B2B). The company wanted to perform a customer portfolio analysis in order to determine which of its customers were profitable and worth developing its relationship with, and conversely, which customers were better let go of. In addition, the company wanted to determine which groups of customers purchased which products. Overall, the strategic goal was to create a tool to be used by the sales department in order to adjust company marketing practices, i.e., to determine suitable marketing effort levels for different, previously unknown, categories of customers.

The data were extracted from the case company's data warehouse and consist of data about customers and their purchasing behavior. The customers are companies from different lines of business, e.g., service, construction, industrial, wholesale, and retail. The data originate from the customers' annual reports and the case company's own data warehouse. They contain descriptive categories, describing the attributes of the customers, as well as sales information concerning the major products.

Based upon a pilot test of the data and a review in cooperation with the case company, a number of small and very large customers (appearing as outliers in the results) were removed, and some product categories with small and infrequent purchases were merged. The motivation for doing this was that the largest customers are already individually served by an own sales representative, and the smallest customers were usually one-time purchasers.

The descriptive categories consisted of: 
- Risk factor, which is an internally calculated measure of potential financial losses

- Company age

- Solvency, which was calculated from the financial statement

- Turnover

- Change in turnover (\%), compared to the previous year

- Balance sheet total, which serves as a measure of company size

- Return on equity (ROE), which was calculated from the financial statement.

The product categories consisted of 18 different products, labeled products A-R. The products are generally speaking information service products, where product I (a significant consulting service) is the most expensive product and product L (a simple filtered data product) is the cheapest one. Product $\mathrm{O}$ stands for overall purchases of products and product $\mathrm{R}$ for other products (one-time analyses and other products difficult to categorize). The data collected were for the period of 2002 to 2006.

The data set contained 1,841 customers, i.e. 9,205 rows of data. $12.8 \%$ of the customers had incomplete descriptive data, i.e., $3.6 \%$ of the data values were missing. The missing data were not considered a problem, as the SOM is able to deal with small amounts of missing data (Bigus 1996).

\section{The SOM}

Artificial neural networks (ANNs) have been widely applied to various business problems ( Smith and Gupta 2002; Vellido et al. 1999b). ANNs are commonly divided into two main categories: supervised and unsupervised learning approaches (Haykin 1999). Supervised networks learn patterns by using target outcomes, and are thus most often used for classification tasks, i.e., where classes are predetermined. Market-driven segmentation would be performed using supervised learning ANNs.

Unsupervised learning is used for exploratory analysis, clustering, and visualization (Kohonen 1998). Kohonen's Self-Organizing Map (SOM) is the most commonly used unsupervised ANN. The SOM is a twolayer feedforward network, in which each neuron learns to recognize a specific input pattern (Kohonen 2001). Each neuron is represented by a prototype vector, i.e. an $n$-dimensional weight vector. The algorithm is basically a two-step process; in the first step, the best matching neuron (BMU, best matching unit) for an input data row is located on the map, and secondly, it and its surrounding neurons within a certain neighborhood radius are tuned to better match (i.e., learn from) the input data, based upon a learning rate factor. The process is repeated until a certain stopping criterion is reached, for example, the training length. The result of the training process is a visual clustering that shows similarities and dissimilarities in the data (Kohonen 2001).

Essentially, the SOM is a nonlinear projection technique that displays high-dimensional data on a twodimensional grid, by preserving the relationships (or topology) in the data but not the actual distances (Deboeck and Kohonen 1998). Commonly, the SOM is visualized using the U-matrix (Unified Distance Matrix) of the map, which displays the Euclidean distances between neurons in shades of color (Ultsch 1993).

From the perspective of segmentation-based CPA, the SOM has several advantages. Compared to mathematical optimization methods and most statistical approaches, the main advantage of the SOM is that it is a highly visual method. This makes it simple to present and explain results to business decision makers. Also, judging the results is more intuitive for a non-mathematically inclined audience. The SOM is also very robust, requiring very little preprocessing of the data, and unlike most statistical approaches, is non-parametric. The SOM is an explorative tool, meaning that very little $a$ priori knowledge is required, and it is possible to uncover unexpected patterns in data. Decision trees are simple to use and highly visual approaches, but correctly deciding the split lines is imperative (Pyle 1999), and they are unsuitable to exploratory analysis where no predefined classes exist. Regression approaches and classification-based neural networks are also unable to deal with data when predefined classes are not available.

The SOM has been widely applied in finance, economy and marketing (Kaski et al. 1998; Kohonen 1998; Oja et al. 2003). For example, the SOM has been used for financial benchmarking (Back et al. 1998; Eklund et al. 2003), macro-economic analysis (Kaski and Kohonen 1996; Länsiluoto 2007), and bankruptcy prediction (Back et al. 1995; Kiviluoto 1998; Martín-del-Brío and Serrano-Cinca 1993). However, regardless of its obvious benefits, the SOM has not been widely applied in customer segmentation tasks. Examples include Rushmeier et al. (1997), who used the SOM to visualize demographic customer segments for marketing purposes, Vellido et al. (1999a), who used the SOM for demographic segmentation of online customers, Lee et al. (2004; 2005), who used the SOM for demographic segmentation of online gamers, and Lingras et al. (2005), who used the SOM for temporal analysis of supermarket customers during a period of 24 hours. This study differs from the previous 
ones in that the SOM is here used for CPA, based upon demographic information as well as product sales information, and for multiple years of data. To our knowledge, this has not been done previously.

\section{TRAINING THE MODEL}

Viscovery SOMine 4.0 (http://www.viscovery.net/) was used to train the maps in this study. SOMine is based upon the batch-SOM training algorithm (Kohonen 2001) and also uses a stepwise increasing map size during the training process, which makes it a very efficient implementation of the SOM algorithm (Deboeck 1998). In addition, SOMine is very user friendly and includes a number of advanced data pre-processing and analysis tools, such as automated clustering of the map based upon Ward's hierarchical clustering method.

The demographic data of the companies (risk factor, age, solvency, turnover, change in turnover\%, balance sheet total, and ROE) were first used to create one map. The results of the demographic segmentation were then matched with the sales information for each product.

Even though the SOM is fairly tolerant towards noisy or missing data (Bigus 1996; Smith and Gupta 2002), data pre-processing is an important part of the data-mining task. Pre-processing refers to the task of dealing with data quality issues such as missing, erroneous, or outlier data ( Berson et al. 2000; Famili et al. 1997; Hand et al. 2001; Pyle 1999). In this application, sigmoid (or logistic) transformation (Bishop 1995) was used to deal with outlier data. The sigmoid transformation was used because it emphasizes the centre input values while reducing the influence of extreme input values (Bishop 1995; Larose 2005). Variance scaling was further used to make the variables comparable.

Generally speaking, the size of the map is dependent upon the purpose of the application. A large hexagonal map is good for visualization (more accurate on the individual record level), whereas a small map is more suitable for clustering (squeezes data into a smaller number of groups) (Desmet 2001; Kohonen 2001). In this case, a map size of 700 nodes was selected as a balance between clustering and visualization since the groups were not expected to be very homogeneous and we wanted to be able to accurately judge the intra-cluster differences. As the software uses the batch SOM algorithm, the learning rate does not need to be specified (Deboeck 1998), and the only other parameter required is the tension. The tension is essentially a value for the neighborhood radius in the final training stage, where a small tension results in high local detail (accuracy), while a high tension has an averaging (smoothing) effect on the map. In this case, the default value 0.5 (average) was used. The neighborhood function is always Gaussian.

Although the U-Matrix of the SOM can be manually interpreted to identify the clusters, two-stage clustering (Vesanto and Alhoniemi 2000) is an easier and more objective method of identifying the clusters on the map. In two-stage clustering, the neurons on the map are clustered based upon their Euclidean distances, using a suitable clustering algorithm. In this case, Ward's hierarchical clustering method, included in the SOMine software, was used to identify the clusters on the final map. The final map is displayed in Figure 1. The clustering of the map resulted in ten clusters of various sizes, labeled C1-C10. The color of the cluster only signifies cluster membership, and does not imply any value. 


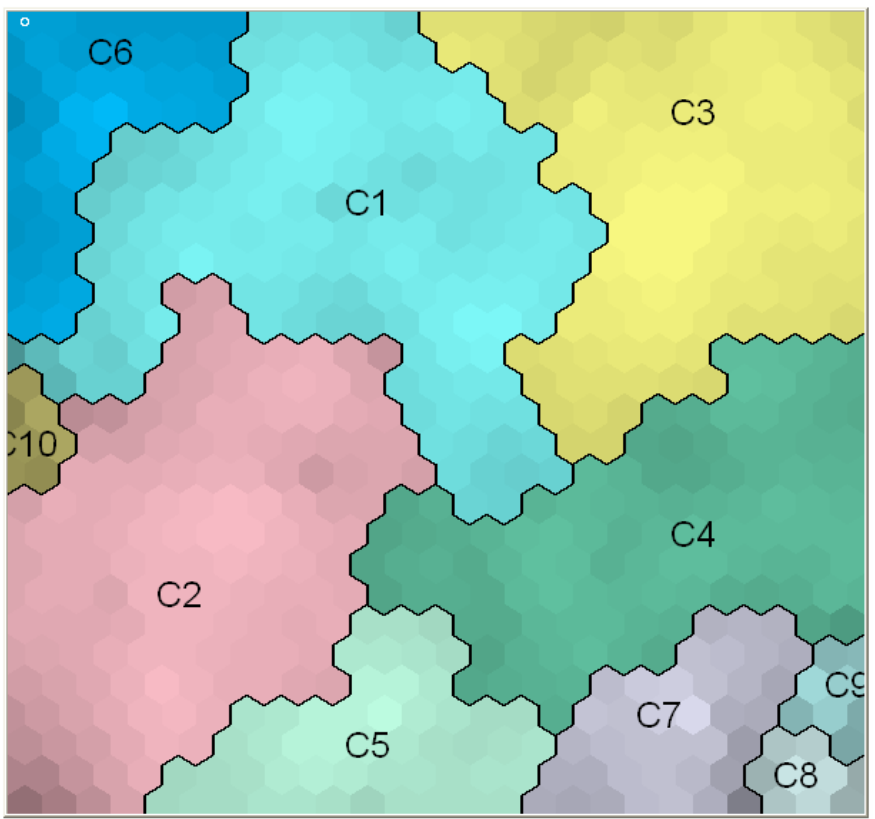

Figure 1: A U-matrix of the segmentation results, using the customer data from years 2002-2006. The map was created according to the variables from the descriptive categories

In order to interpret the map, and in particular the characteristics of each cluster, the component planes (displayed in Figure 2) of the map must be used. The component planes show the distribution of values across the map, according to one variable at a time. The values according to one variable are displayed by the color of the neuron, where "warm" colors (red, orange, and yellow) illustrate high values and "cool" colors (blue) illustrate low values. The approximate values are indicated by the scale under each component plane. The map is interpreted by reading the component planes for each cluster. For example, Cluster 6 displays medium to high values in solvency and ROE, and low values in age, turnover, and balance sheet total. Cluster 6 also shows varying risk factors, from low to high. We can conclude that these are fairly young and small companies, although very profitable. We can also see that the risk factor is extremely large in segments C2 and C5, which means that these segments contain less reliable companies. The oldest companies are found in segments C4, C5 and C7.
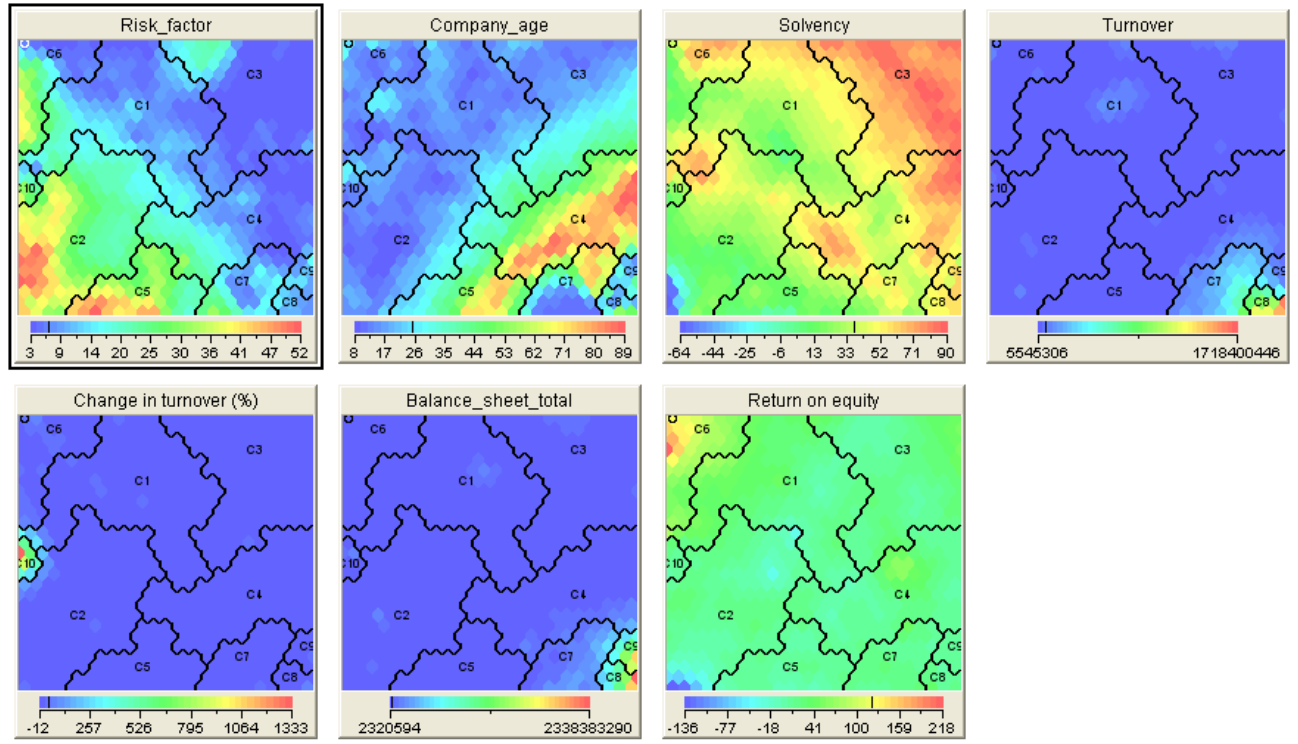

Figure 2: The component planes of the map, showing the values according to one component at a time 


\section{ANALYSIS OF THE RESULTS}

The results of the customer segmentation are summarized in Table 1, which shows the sizes and distinguishing features of each of the clusters. Clusters C1, C2 and C3 are the largest ones.

Table 1. Division of customers into clusters according to the segmentation presented in Figure 1

\begin{tabular}{|c|c|c|c|c|}
\hline Clusters & Customers & $\%$ & Distinguishing feature(s) & Purchased products \\
\hline Cluster 1 & 1,659 & 20.68 & No specific attribute & A-R, except M \\
\hline Cluster 2 & 1,689 & 21.05 & High risk factor & A-R, except M \\
\hline Cluster 3 & 1,699 & 21.17 & Highest solvency & A-R, except M \\
\hline Cluster 4 & 1,139 & 14.19 & Oldest companies, high solvency & A-R, except M \\
\hline Cluster 5 & 640 & 7.98 & Large companies, high solvency & A-R, except M \& Q \\
\hline Cluster 6 & 565 & 7.04 & $\begin{array}{l}\text { High risk factor, good solvency, } \\
\text { very high profitability }\end{array}$ & A-R, except M \\
\hline Cluster 7 & 398 & 4.96 & $\begin{array}{l}\text { Both old and young companies, } \\
\text { good turnover }\end{array}$ & A-R, except $\mathrm{M}$ \\
\hline Cluster 8 & 91 & 1.13 & $\begin{array}{l}\text { Largest turnover, large balance sheet } \\
\text { total }\end{array}$ & A-R, except M \& Q \\
\hline Cluster 9 & 80 & 1.00 & Large balance sheet total & A-R, except L \& M \\
\hline Cluster 10 & 64 & 0.80 & Largest change in turnover (\%) & A-R, except M \& Q \\
\hline
\end{tabular}

The clusters identified are as follows:

- Cluster 1: an average group with no specifically identifying characteristics. Risk factor, age, turnover, and balance sheet total are low, and solvency is medium to high. Return on equity is good on average. One of the three largest groups in terms of number of customers.

- Cluster 2: exhibits a considerably higher risk factor, lower solvency, and lower return on equity than in Cluster 1. This group also contains the customers with the lowest return on equity, as well as the companies with the lowest solvency. One of the three largest groups in terms of number of customers.

- $\quad$ Cluster 3: similar to Cluster 1 except for a considerably higher solvency. The average company age is somewhat higher, although risk factor seems to be similar to that of Cluster 1 . One of the three largest groups in terms of number of customers.

- Cluster 4: contains the oldest companies in the dataset, and generally exhibits a high solvency and good profitability.

- Cluster 5: is a mid-size cluster containing larger than average companies. Solvency is good, and the companies are fairly new. Profitability is average.

- Cluster 6: a mid-size cluster that contains the most profitable companies in the dataset. In general small, growing companies. Nearly half of the cluster displays a very high risk factor, but some companies are also very solvent.

- $\quad$ Cluster 7: a mid-size cluster that contains fairly large companies in terms of turnover and total assets. Solvency is good on average, and the cluster contains a mix of old and new companies.

- Cluster 8: is one of the three small clusters and contains the largest companies in terms of assets and turnover. The companies are solvent and fairly profitable, and their risk factor is very low. Company age is above average.

- Cluster 9: is another small group of large companies. This cluster differs from Cluster 8 in that the companies are newer and turnover is lower.

- Cluster 10: is the smallest and final cluster identified. It contains rapidly growing companies that are fairly profitable and solvent, and have a fairly low risk factor.

After the clusters were identified, the next step was to compare the sales information for each product category to the created segments. The full table can be found in Appendix 1. The color scale in Appendix 1 visualizes 
how the clusters can be divided into groups consisting of the largest, average, and smallest customers according to the sales information. If the amount of sales work expended for each of the segments is the same, the division of the customer segments can be extended to describe profitable, average and non-profitable customers.

\section{Largest customers in terms of sales}

The largest customers are located in clusters C7 and C8. $6.1 \%$ of the companies in the customer base belong to this group. These companies have the largest average sales figures for nearly every product. In the SOM map presented in Figure 1, these clusters are located in the lower right corner of the map. There are both young and old companies that possess a large turnover in Cluster 7. Some of the younger companies in this segment have a slightly higher risk factor, and some of the customers have a high solvency. The large balance sheet total for the customers in Cluster 8 is a sign that these companies are large in size. These companies have the largest turnover and a high solvency.

\section{Average customers in terms of sales}

According to the segmentation model, the average customers in terms of sales are located in clusters C1, C4, C6, C9 and C10. They constitute $43.7 \%$ of the total customer base. The companies in Cluster 1 do not have a dominating descriptive component. A small part of the customers in this cluster has an increased risk factor, another part is slightly older, and a third part has a good solvency. The oldest customers are located in cluster C4. These have a high solvency, and some of them have an increased risk factor. The companies in Cluster 6 have a high risk factor, but they possess a high solvency and the largest return on equity. The companies in Cluster 9 are large in size, as they have a large balance sheet total. The customers in Cluster 10 are growing companies. Also, the specific company that makes the highest overall purchases belongs to this cluster.

The order of priority for these average clusters, according to the information gained from the segmentation, would be as follows: clusters C10 and C9 (made most purchases), Cluster 4 (average) and clusters C1 and C6 (made least purchases). According to the model, Cluster 9 is very similar to the clusters with the companies who conducted most purchases, i.e., clusters C7 and C8. This would indicate the possibility that future good customers could be found in Cluster 9. Similarly, the poorest customers in this group are located in Cluster 6, which is very different from the best performing clusters.

\section{Poorest customers in terms of sales}

The companies in clusters C2, C3 and C5 are the poorest customers, i.e., they purchase the least amount of products. Their share of the customer base is $50.3 \%$ and these customers, therefore, constitute the largest group. According to the model, the companies in Cluster 2 have a high risk factor. However, many of the single companies that have purchased the largest amounts of a specific product are located in this cluster. The customers in cluster C3 have the highest solvency. A small share of these companies has a slightly increased risk factor, and another share is slightly older. The companies in Cluster 5 are older with a high risk factor. A common factor amongst the poorest customers is the high risk factor, which means that they are not reliable customers.

\section{CONCLUSIONS AND FUTURE RESEARCH}

In this paper, the use of the SOM for customer portfolio analysis has been illustrated. A customer segmentation based upon demographic data was performed using the SOM, identifying ten clusters of customers displaying different demographic characteristics. The resulting clusters were then coupled with sales data, and a customer portfolio analysis was performed in order to identify profitable and unprofitable customers. The resulting model was face validated by experts from the sales department of the case organization. The sales department of the case organization could potentially develop its marketing strategies based on the results of this work.

There are several interesting topics of research that should be pursued in the future. Firstly, the model cannot identify a universal demographic feature or set of features that can predict customer profitability, although customer size gives an indication of purchase potential. Further research should be conducted to see if the addition of other demographic features could increase the predictive performance of the model. Secondly, predicting purchase potential is potentially a valuable addition to the model. This could be done using statistical models. Thirdly, predicting the level of effort required to push a customer to a more profitable level of relationship should be researched, e.g., using Markov chain analysis. Finally, market basket analysis was preliminarily performed in Holmbom (2007), and should be further developed. 


\section{REFERENCES}

Back, B., Sere, K., and Vanharanta, H. 1998. "Managing Complexity in Large Data Bases using Self-Organizing Maps," Accounting Management and Information Technologies (8:4), October, pp 191-210.

Back, B., Oosterom, G., Sere, K., and van Wezel, M. 1995. "Intelligent Information Systems within Business: Bankruptcy Predictions using Neural Networks," in The 3rd European Conference on Information Systems (ECIS'95), June 1-3, Athens, Greece: pp 99-111.

Berry, M. J. A., and Linoff, G. S. 2004. Data Mining Techniques: For Marketing, Sales, and Customer Relationship Management. Indianapolis, Indiana: Wiley Publishing Inc.

Berson, A., Smith, S., and Thearling, K. 2000. Building Data Mining Applications for CRM. USA: McGrawHill Companies Inc.

Bigus, J. P. 1996. Data Mining with Neural Networks: Solving Business Problems from Application Development to Decision Support. New York, NY: The McGraw-Hill Companies Inc.

Bishop, C. M. 1995. Neural Networks for Pattern Recognition. Avon: Oxford University Press.

Buttle, F. 2004. Customer Relationship Management Concepts and Tools. Oxford: Butterworth-Heinemann.

Chalmeta, R. 2006. "Methodology for Customer Relationship Management," The Journal of Systems and Software (79:7), July, pp 1015-1024.

Datta, Y. 1996. "Market Segmentation: An Integrated Framework," Long Range Planning (29:6), December, pp 797-811.

Deboeck, G. J. 1998. "Software Tools for Self-Organizing Maps," In Visual Explorations in Finance using SelfOrganizing Maps, Deboeck, G. J. and Kohonen, T. (eds.), Berlin: Springer-Verlag, pp 179-194.

Deboeck, G. J., and Kohonen, T. 1998. Visual Explorations in Finance with Self-Organizing Maps. Berlin: Springer-Verlag.

Desmet, P. 2001. "Buying Behavior Study with Basket Analysis: Pre-Clustering with a Kohonen Map," European Journal of Economic and Social Systems (15:2), pp 17-30.

Eklund, T., Back, B., Vanharanta, H., and Visa, A. 2003. "Using the Self-Organizing Map as a Visualization Tool in Financial Benchmarking," Information Visualization (2:3), September, pp 171-181.

Famili, A., Shen, W.-M., Weber, R., and Simoudis, E. 1997. "Data Preprocessing and Intelligent Data Analysis," Intelligent Data Analysis (1:1), pp 3-23.

Frank, R. E., Massy, W. F., and Wind, Y. 1972. Market Segmentation. Englewood Cliffs, New Jersey: Prenticehall Inc.

Hand, D. J., Mannila, H., and Smyth, P. 2001. Principles of Data Mining. Boston, USA: MIT Press, 2001.

Haykin, S. 1999. Neural Networks - A Comprehensive Foundation. Upper Saddle River, N.J.: Prentice Hall International, Inc.

Heinrich, B. 2005. "Transforming Strategic Goals of CRM into Process Goals and Activities," Business Process Management Journal (11:6), pp 709-723.

Holmbom, A. H. 2007. Identifying Customer Segments using the Self-Organizing Map, Unpublished Master's thesis. Turku, Finland: Abo Akademi University.

Kaski, S., Kangas, J., and Kohonen, T. 1998. "Bibliography of Self-Organizing Map (SOM) Papers 1981-1997," Neural Computing Surveys (1), pp 102-350.

Kaski, S., and Kohonen, T. 1996. "Exploratory Data Analysis by the Self-Organizing Map: Structures of Welfare and Poverty in the World," In Neural Networks in Financial Engineering, Apostolos, P. N. R., AbuMostafa, Y., Moody, J. and Weigend, A. (eds.), Singapore: World Scientific, pp 498-507.

Kim, S., Jung, T., Suh, E., and Hwang, H. 2006. "Customer Segmentation and Strategy Development Based on Customer Lifetime Value: A Case Study," Expert Systems with Applications (31:1), July, pp 101-107.

Kiviluoto, K. 1998. "Predicting Bankruptcies with the Self-Organizing Map," Neurocomputing (21:1-3), November, pp 191-201.

Kohonen, T. 2001. Self-Organizing Maps. Berlin: Springer-Verlag. 
Kohonen, T. 1998. "The SOM Methodology," In Visual Explorations in Finance: With Self-Organizing Maps, Deboeck, G. J. and Kohonen, T. (eds.), Berlin: Springer Verlag, pp 159-167.

Länsiluoto, A. 2007. "Suitability of Self-Organising Maps for Analysing a Macro-Environment - an Empirical Field Survey," International Journal of Business Information Systems (2:2), December, pp 149-161.

Larose, D. T. 2005. Discovering Knowledge in Data. an Introduction to Data Mining. Hoboken, NJ: John Wiley \& Sons Inc.

Lee, S. C., Suh, Y. H., Kim, J. K., and Lee, K. J. 2004. "A Cross-National Market Segmentation of Online Game Industry using SOM," Expert Systems with Applications (27:4), November, pp 559-570.

Lee, S. C., Xiang, J. Y., and Jing, L. B. 2005. "Who are the Target Customers in Chinese Online Game Market?: Segmentation with a Two-Step Approach," in Proceedings of the 2005 IEEE International Conference on eBusiness Engineering, Beijing, China, IEEE, pp 736-743.

Lingras, P., Hogo, M., Snorek, M., and West, C. 2005. "Temporal Analysis of Clusters of Supermarket Customers: Conventional Versus Interval Set Approach," Information Sciences (172:1-2), June, pp 215-240.

Martín-del-Brío, B., and Serrano-Cinca, C. 1993. "Self-Organizing Neural Networks for the Analysis and Representation of Data: Some Financial Cases," Neural Computing and Applications (1:2), September, pp 193-206.

Oja, M., Kaski, S., and Kohonen, T. 2003. "Bibliography of Self-Organizing Map (SOM) Papers: 1998-2001 Addendum," Neural Computing Surveys (3), pp 1-156.

Paas, L., and Kuijlen, T. 2001. "Towards a General Definition of Customer Relationship Management," Journal of Database Marketing (9:1), pp 51-60.

Park, H., and Baik, D. 2006. "A Study for Control of Client Value using Cluster Analysis," Journal of Network and Computer Applications (29:4), November, pp 262-276.

Pyle, D. 1999. Data Preparation for Data Mining. San Diego, CA: Academic Press.

Rushmeier, H., Lawrence, R., and Almasi, G. 1997. "Case Study: Visualizing Customer Segmentations Produced by Self Organizing Maps," in Eighth IEEE Visualization 1997 (VIS'97), Phoenix, AZ, USA, pp 463-466.

Rygielski, C., Wang, J. -., and Yen, D. C. 2002. "Data Mining Techniques for Customer Relationship Management," Technology in Society (24:4), pp 483-502.

Shaw, M. J., Subramaniam, C., Tan, G. W., and Welge, M. E. 2001. "Knowledge Management and Data Mining for Marketing," Decision Support Systems (31:1), pp 127-137.

Smith, K., and Gupta, J. 2002. Neural Networks in Business. Hershey, PA: IDEA Group Publishing.

Terho, H., and Halinen, A. 2007. "Customer Portfolio Analysis Practices in Different Exchange Contexts," Journal of Business Research (60:7), July, pp 720-730.

Tsai, C.-Y., and Chiu, C.-C. 2004. "A Purchase-Based Market Segmentation Methodology," Expert Systems with Applications (27:2), August, pp 265-276.

Turnbull, P. W. 1990. "A Review of Portfolio Planning Models for Industrial Marketing and Purchasing Management," European Journal of Marketing (24:3), pp 7-22.

Ultsch, A. 1993. "Self Organized Feature Planes for Monitoring and Knowledge Acquisition of a Chemical Process," in The International Conference on Artificial Neural Networks (ICANN93), Springer-Verlag: London, pp 864-867.

Vellido, A., Lisboa, P. J. G., and Meehan, K. 1999a. "Segmentation of the on-Line Shopping Market using Neural Networks," Expert Systems with Applications (17:4), pp 303-314.

Vellido, A., Lisboa, P. J. G., and Vaughan, J. 1999b. "Neural Networks in Business: A Survey of Applications (1992-1998)," Expert Systems with Applications (17:1), pp 51-70.

Vesanto, J., and Alhoniemi, E. 2000. "Clustering of the Self-Organizing Map," IEEE Transactions on Neural Networks (11:3), May, pp 586-600.

Wedel, M., and Kamakura, W. 1999. Market Segmentation Conceptual and Methodological Foundations. Massachusetts, USA: Kluwer Academic Publishers. 


\section{ACKNOWLEDGEMENTS}

The authors would like to thank the case organization for its participation in the study. The authors also gratefully acknowledge the financial support of the National Agency of Technology (Titan, grant no. 40063/08), the Academy of Finland (Visiting researcher grant no. 125588), and the Foundation for Economic Education (grant no. 27999).

\section{APPENDIX 1}

\begin{tabular}{|c|c|c|c|c|c|c|c|c|c|c|}
\hline Clusters & C1 & C2 & C3 & C4 & C5 & C6 & C7 & C8 & C9 & C10 \\
\hline Product A & & 2. $\min$ & & & $\min$ & & & 2. $\max$ & & $\begin{array}{c}\operatorname{Max} / \\
\operatorname{MaxN} \\
\text { r }\end{array}$ \\
\hline Product B & $\underset{r}{\operatorname{MaxN}}$ & $\min$ & & & & 2.min & Max & 2.max & & \\
\hline Product C & & $\begin{array}{c}\text { Min / } \\
\text { MaxN }\end{array}$ & & & 2.min & & Max & 2.max & & \\
\hline Product D & & & & & $\min$ & & 2. $\max$ & $\begin{array}{c}\operatorname{Max} / \\
\operatorname{MaxN} \\
\mathrm{r}\end{array}$ & 2.min & \\
\hline Product E & $\min$ & $\underset{r}{\operatorname{MaxN}}$ & & & 2.min & & Max & & & 2.max \\
\hline Product F & $\underset{r}{\operatorname{MaxN}}$ & & $\min$ & & & & & 2.max & Max & 2.min \\
\hline Product G & & $\underset{r}{\operatorname{MaxN}}$ & $\min$ & & & & Max & 2.max & & 2.min \\
\hline Product H & & $\begin{array}{c}\operatorname{MaxN} \\
r\end{array}$ & 2.min & & & & Max & 2.max & & $\min$ \\
\hline Product I & & $\min$ & 2.min & & & & $\begin{array}{c}\text { 2.max/ } \\
\text { MaxN } \\
r\end{array}$ & Max & & \\
\hline Product J & & 2.min & & $\begin{array}{c}\text { 2.max/ } \\
\operatorname{MaxN}\end{array}$ & & Min & & Max & & \\
\hline Product K & & $\min$ & & & 2.min & & & $\begin{array}{c}\operatorname{Max} / \\
\operatorname{MaxN} \\
\mathrm{r}\end{array}$ & 2. $\max$ & \\
\hline Product L & $\min$ & $\begin{array}{c}\operatorname{MaxN} \\
\mathrm{r}\end{array}$ & 2. $\min$ & & & & & 2. $\max$ & 0 & Max \\
\hline Product M & 0 & 0 & 0 & 0 & 0 & 0 & 0 & 0 & 0 & 0 \\
\hline Product N & & & & $\begin{array}{c}\operatorname{MaxN} \\
r\end{array}$ & $\min$ & 2. $\max$ & & Max & & 2.min \\
\hline $\begin{array}{l}\text { Overall } \\
\text { purchases }\end{array}$ & $\underset{r}{\operatorname{MaxN}}$ & 2.min & $\min$ & & & & Max & 2.max & & \\
\hline Product P & & 2.min & & $\underset{r}{\operatorname{MaxN}}$ & & Min & 2. $\max$ & Max & & \\
\hline Product Q & & & & 2. $\max$ & 0 & & $\begin{array}{c}\operatorname{Max} / \\
\operatorname{MaxN} \\
\text { r }\end{array}$ & 0 & & 0 \\
\hline Product R & & $\min$ & 2.min & $\begin{array}{c}\operatorname{MaxN} \\
r\end{array}$ & & & $\operatorname{Max}$ & & 2.max & \\
\hline
\end{tabular}


Clusters with the two customers making most of the purchases (MAX, 2.MAX) were marked with warm colors, i.e. different shades of red, and respectively, clusters with the two least purchasing customers (min, 2.min) were marked with cool blue colors. The comparison was made according to average cluster sales. Also, the cluster where the company that purchased the most, measured in $€$, is located was marked for each of the products separately (MaxNr).

\section{COPYRIGHT}

Holmbom, Eklund and Back (C) 2008. The authors assign to ACIS and educational and non-profit institutions a non-exclusive licence to use this document for personal use and in courses of instruction provided that the article is used in full and this copyright statement is reproduced. The authors also grant a non-exclusive licence to ACIS to publish this document in full in the Conference Papers and Proceedings. Those documents may be published on the World Wide Web, CD-ROM, in printed form, and on mirror sites on the World Wide Web. Any other usage is prohibited without the express permission of the authors. 